\title{
Targeted treatment of folate receptor-positive platinum-resistant ovarian cancer and companion diagnostics, with specific focus on vintafolide and etarfolatide
}

\author{
This article was published in the following Dove Press journal: \\ Pharmacogenomics and Personalized Medicine \\ 29 January 2014 \\ Number of times this article has been viewed
}

\section{Loredana Serpe \\ Margherita Gallicchio \\ Roberto Canaparo \\ Franco Dosio}

Department of Drug Science and Technology, University of Turin, Italy
Correspondence: Franco Dosio Department of Drug Science and Technology, University of Turin, Italy, v. Pietro Giuria 9, 10125 Turin, Italy

Tel +39 ol 16707082

Fax +39 0I I2367697

Email franco.dosio@unito.it

\begin{abstract}
Among the gynecological malignancies, ovarian cancer is the leading cause of mortality in developed countries. Treatment of ovarian cancer is based on surgery integrated with chemotherapy. Platinum-based drugs (cisplatin and carboplatin) comprise the core of first-line chemotherapy for patients with advanced ovarian cancer. Platinum-resistant ovarian cancer can be treated with cytotoxic chemotherapeutics such as paclitaxel, topotecan, PEGylated liposomal doxorubicin, or gemcitabine, but many patients eventually relapse on treatment. Targeted therapies based on agents specifically directed to overexpressed receptors, or to selected molecular targets, may be the future of clinical treatment. In this regard, overexpression of folate receptor- $\alpha$ on the surface of almost all epithelial ovarian cancers makes this receptor an excellent "tumor-associated antigen". With appropriate use of spacers/linkers, folate-targeted drugs can be distributed within the body, where they preferentially bind to ovarian cancer cells and are released inside their target cells. Here they can exert their desired cytotoxic function. Based on this strategy, 12 years after it was first described, a folate-targeted vinblastine derivative has now reached Phase III clinical trials in ovarian cancer. This review examines the importance of folate targeting, the state of the art of a vinblastine folate-targeted agent (vintafolide) for treating platinum-resistant ovarian cancer, and its diagnostic companion (etarfolatide) as a prognostic agent. Etarfolatide is a valuable noninvasive diagnostic imaging agent with which to select ovarian cancer patient populations that may benefit from this specific targeted therapy.
\end{abstract}

Keywords: vintafolide, etarfolatide, platinum-resistant ovarian cancer, targeted therapy, biomarkers, folate receptor

\section{Introduction to ovarian cancer}

Ovarian carcinoma is the most lethal gynecological cancer worldwide. ${ }^{1}$ The World Health Organization GLOBOCAN database reported a worldwide incidence of around 200,000 cases of ovarian cancer in 2008, with a 5-year survival rate of $30 \%-92 \%$ depending on the disease spread at diagnosis. A variety of factors influence the risk of developing ovarian cancer (Table 1). A positive family history of ovarian or breast cancers is the most important factor, and nulliparity is also associated with an increased risk of ovarian cancer. ${ }^{2}$ Evidence concerning the effect of hormone replacement therapy on the risk of developing ovarian cancer has to date been conflicting, although a meta-analysis has associated use of hormone replacement therapy with an increased risk of ovarian carcinoma. ${ }^{3}$ Other factors suggested to be associated with an increased risk of epithelial ovarian carcinoma, but for which the evidence is less 
Table I Risk factors for developing ovarian cancer

\begin{tabular}{ll}
\hline Increased risk & Decreased risk \\
\hline Age & Oral contraceptive use \\
High-fat diet & Pregnancy \\
Inherited predisposition & Lactation \\
Nulliparity & \\
Ovulation & \\
Pelvic inflammatory disease & \\
Polycystic ovarian disease & \\
\hline
\end{tabular}

robust, include infertility, ${ }^{4}$ pelvic inflammatory disease, ${ }^{5}$ polycystic ovaries, ${ }^{6}$ obesity, ${ }^{7}$ and animal fat consumption. ${ }^{8,9}$ Conversely, oral contraceptive use, pregnancy, and lactation are associated with a reduced risk. ${ }^{10}$

About $90 \%$ of ovarian tumors are epithelial in origin, while the remainder comprises germ or stromal tumors. The World Health Organization classification describes three major types of epithelial adenocarcinoma, ie, serous, mucinous, and endometrioid. There is some evidence that the prognosis for women with a diagnosis of mucinous epithelial ovarian cancer is worse than for those with a diagnosis of serous histology, and the prognosis of patients with clear-cell histology is unlikely to be better. ${ }^{11,12}$ Treatment of ovarian cancer is based on surgery integrated with chemotherapy. ${ }^{13}$ Chemotherapy plays a major role both in adjuvant treatment and in the care of patients with advanced disease. Platinum-based drugs (cisplatin and carboplatin) are the core of first-line chemotherapeutics for patients with advanced ovarian cancer. ${ }^{14}$ Several drugs have been combined with cisplatin or carboplatin in an attempt to improve survival, and large clinical trials have confirmed the benefits of adding paclitaxel to first-line chemotherapy for woman with advanced ovarian cancer; $;{ }^{15}$ however, ovarian cancer continues to be characterized by stagnant mortality statistics.

A clear difference has been found between serous and nonserous carcinomas in terms of folate receptor (FR) expression, in particular that of overexpression of the FR $\alpha$ isoform on the surface of almost all epithelial ovarian cancers, making it an excellent "tumor-associated antigen" for tackling one of the most important challenges in ovarian cancer treatment, ie, platinum-resistant disease. ${ }^{16}$ For a recent review of current approaches to treating platinum-resistant ovarian cancer, see Leamon et al. ${ }^{17}$ This review examines targeted treatment of FR $\alpha$ in women with platinum-resistant ovarian cancer, focusing especially on vintafolide and etarfolatide. The term "platinum-resistant" is now used to describe patients whose disease recurrence is documented within 6 months of platinum-based therapy; ${ }^{18,19}$ unfortunately these patients have a poor prognosis, and thus novel compounds and approaches, including new treatment options that are more selective and more individualized in their approach are welcome.

\section{Personalized medicine in oncology}

As defined by the USA President's Council on Advisors on Science and Technology,

"Personalized Medicine refers to the tailoring of medical treatment to the individual characteristics of each patient ... to classify individuals into subpopulations that differ in their susceptibility to a particular disease or their response to a specific treatment. Preventive or therapeutic interventions can then be concentrated on those who will benefit, sparing expense and side effects for those who will not." ${ }^{20}$

The concept of personalized medicine is closely related to the concept of targeted therapy, given that the possibility to treat each patient in the best way is linked to the possibility of recognizing a specific molecular target to drive selective drugs. Undoubtedly, oncology is a promising field for this kind of approach, because molecular targets that are specific for a particular tumor can frequently be identified. The objective of personalized cancer treatment is to select the ideal therapy for an individual cancer patient, based on knowledge of that patient's tumor characteristics and/or genetics. The first example of application of targeted therapy was imatinib, a tyrosine kinase inhibitor that can improve survival in patients with chronic myelogenous leukemia and who carry a particular translocation in their leukemic white blood cells. ${ }^{21}$ Another example of an application of targeted therapy concerns colorectal cancer, for which drugs targeting epidermal growth factor receptor, such as cetuximab or panitumumab, or those targeting vascular endothelial growth factor, such as bevacizumab, have entered routine clinical use. ${ }^{22-24}$ The FR is thus a valuable therapeutic target in ovarian cancer since it is highly expressed on a variety of cancers, whereas it is largely absent from normal tissue. The identification of FR $\alpha$ as a molecular target may lead to the development of drugs, specifically targeted to ovarian cancer cells.

\section{Introduction to the folate receptor}

FRs are cysteine-rich cell surface glycoproteins that bind folate with high affinity. Three FR isoforms have been identified to date, ie, FR $\alpha, F R \beta$, and FR $\gamma$. In 2000, Spiegelstein et al, through genome database mining, identified a fourth isoform, FR $\delta$, but neither its tissue expression nor its functionality as a folate binder has been clearly established. ${ }^{25}$ These receptors actually comprise a family of proteins, since they share highly conserved sequences and are all 
encoded by the folate receptor multigene family, which is localized on chromosome 11q13.3-q14.1. ${ }^{26}$

FR $\alpha$ and FR $\beta$ are the most studied isoforms; they are membrane-anchored receptors and mediate internalization of receptor-bound folate compounds and folate conjugates..$^{27-30}$ FR $\gamma$ is primarily a secretory protein, in that it lacks an efficient signal for glycosylphosphatidylinositol (GPI) modification. ${ }^{31}$ FR $\alpha$ and FR $\beta$, in particular, are colocalized in lipid rafts, ie, membrane microdomains that function as platforms able to recycle GPI-anchored proteins. ${ }^{32}$ All FR isoforms bind folic acid with high affinity $(\mathrm{Kd}<1 \mathrm{nM})$. In contrast, $\mathrm{FR} \alpha$ and $\mathrm{FR} \beta$ display different affinities towards reduced folate isoenzymes; for example, FR $\alpha$ has 50 times greater affinity than FR $\beta$ for N5-methyltetrahydrofolate. This difference is correlated with the different amino acid composition of the two receptors, namely Leu-49 in FR $\beta$, and Ala-49, Val-104, and Glu-166 in FR $\alpha .{ }^{33,34}$

In 1986, Elwood et al identified a soluble high-affinity folate-binding protein in the KB human nasopharyngeal cell line, ${ }^{35}$ which was also isolated from extracellular fluids such as human milk ${ }^{36}$ and human placenta. ${ }^{37}$ It has been shown that soluble high-affinity folate-binding protein may originate from FR $\alpha$ or from FR $\beta$, as well as from FR $\gamma^{34}$ That soluble highaffinity folate-binding protein can originate from $\mathrm{FR} \alpha$ was demonstrated in $\mathrm{KB}$ and placenta cells, where it was derived either by proteolysis mediated via an $\mathrm{Mg}^{2+}$-dependent protease or by phospholipase cleavage of the GPI anchor. ${ }^{38,39} \mathrm{FR} \beta$ is processed intracellularly via two independent pathways; one results in GPI anchor addition and the other results in its secretion. ${ }^{40}$

\section{Specific role of FR in ovarian cancer}

The significance of this receptor as a tumor marker was discovered in 1991 when, through amino acid sequence analysis, a protein enriched on the surface of a human ovarian carcinoma cell line was shown to be the FR. ${ }^{41}$ The FR was later shown to be expressed on the majority of nonmucinous ovarian carcinomas, and subsequent analyses have revealed more marked upregulation of the FR $\alpha$ isoform than of the other isoforms in ovarian carcinoma. ${ }^{42,43}$ It has been suggested that FR $\alpha$ might confer a growth advantage on the tumor by modulating folate uptake from serum, which in turn might facilitate rapid cellular growth and division. Alternatively, it has been suggested that FR $\alpha$ might affect cell proliferation via cell signaling pathways, similarly to other cellular membrane proteins with a GPI anchor. ${ }^{44,45}$ It also appears possible that FR $\alpha$ levels may be elevated during the early stages of carcinogenesis, when they would increase folate uptake and stimulate cells to repair DNA damage in transcription factors or in other proteins ${ }^{46}$ The inability of these cells to repair these proteins coding DNA might lead to continued FR $\alpha$ expression, which could eventually support the transition to a cellular environment favoring tumor progression and increasing the tumor folate requirements for rapid growth. ${ }^{47}$

Comparatively little attention has been paid to FR $\alpha$ levels and patient survival in ovarian cancer; in one such study, expression of FR $\alpha$ protein was found to be associated with tumor progression. ${ }^{48}$ In another study it was associated with high-grade ovarian cancers, platinum therapy resistance, and poor prognosis ${ }^{49}$ suggesting that metabolic changes related to its upregulation may occur early in carcinogenesis; the study authors offered some hypotheses to explain their findings, including that FR $\alpha$ may increase folate uptake, which could stimulate cells to repair DNA damage caused by platinum, or that FR $\alpha$ involvement in signal transduction could help cells progress through the cell-cycle phases faster than cells with lower levels of FR $\alpha$, or again that FR $\alpha$ might predispose cells to overcome drug-induced injury, as observed for genes involved in cellular signaling or apoptosis. ${ }^{50,51}$

A recent study ${ }^{16}$ confirmed an FR $\alpha$ expression rate of roughly $82 \%$ in patients with serous ovarian cancer, although expression was marked in a small proportion of these cases. Further, the study authors showed that chemotherapy does not significantly alter FR $\alpha$ expression in vital residual tumor tissue, suggesting an important role for FR $\alpha$ as a target for diagnostic agents and drugs. The limited tissue-specific expression of the FR isoforms enables FR $\alpha$ to be exploited for the selective delivery of cytotoxic agents into malignant cells, with reduced toxic side effects in nontarget tissues.

For these reasons, FR $\alpha$ is an appropriate target for cancer immunotherapy with monoclonal antibody-based reagents. Specific monoclonal antibodies (bearing radioisotopes) may be used for imaging and/or therapeutic purposes (used alone, as bispecific monoclonal antibodies, or after conjugation with toxins, drugs, radionuclides, or cytokines). Several anti-FR $\alpha$ antibodies have been developed, the most interesting being the murine monoclonal antibodies MOv18, MOv19, and LK26. These recognize two noncompeting epitopes of FR $\alpha$, and have been developed by Miotti et $\mathrm{al}^{42}$ and Garin-Chesa et al. ${ }^{52}$ Guided selection of MOv18 or MOv19 resulted in an optimization process that led to a chemical dimer, AFRADFM5.3, now in advanced preclinical evaluation..$^{53}$ An optimized process of humanization of LK26 led to farletuzumab (MORab-003; Morphotek Inc., Exton, PA, USA). In this case, the cytotoxicity of the monoclonal antibody is mediated via complement-dependent cytotoxicity and antibody-dependent cell-mediated cytotoxicity. Promising initial findings led to 
advanced clinical trials (NCT01218516) in platinum-sensitive patients who experienced first relapse to determine the efficacy of farletuzumab as monotherapy and in combination with carboplatin/taxane. ${ }^{54,55}$ Meanwhile, Phase II trials of farletuzumab as a first-line agent in combination with traditional platinum-containing chemotherapies in lung adenocarcinoma are ongoing (NCT01218516). ${ }^{56}$ Recently, a Phase III trial (FAR-122, NCT00738699) of farletuzumab in combination with paclitaxel in advanced platinum-resistant ovarian cancer has been discontinued because of its limited survival benefit for patients. ${ }^{57}$ Additionally, some immune-mediated events were observed. Furthermore, Morphotek Inc has announced that it is actively developing a companion diagnostic assay to identify patients with high FR $\alpha$ expression because these patients may receive more benefit from farletuzumab therapy than those with low FR expression. ${ }^{58}$

The rationale underlying FR $\alpha$-targeted drug delivery lies in the substrate specificity of folic acid versus FR $\alpha$. In this type of approach, folate can be linked to various therapeutic agents, namely low-molecular-weight chemotherapeutic agents, liposomes with entrapped drugs, antisense oligonucleotides, and immunotherapeutic agents, that can then target cancer cells that overexpress FR. ${ }^{59}$ This is possible because folate is amenable to chemical conjugation with other molecules through its $\gamma$-carboxyl group, without decreasing its binding affinity to the FR. ${ }^{60}$ In this connection, Leamon and Low have introduced a novel and personalized approach to identifying patients who are most likely to benefit from FR-targeted therapy (Figure 1). ${ }^{59}$ This strategy has led to the development of several small-molecule drug conjugates to target cells that overexpress all the FR isoforms. ${ }^{61}$ One of the most promising and the one studied in most depth is vintafolide (originally known as EC145), which combines a water-soluble derivative of folic acid (pteroic acid) and desacetylvinblastine hydrazide, a potent vinca alkaloid (Figure 2). ${ }^{62}$ The two molecules are connected in a regioselective manner via a hydrophilic peptide spacer and a self-immolative group based on disulfides as the cleavable linkage. Desacetylvinblastine hydrazide is prepared from vinblastine-free base by reaction with anhydrous hydrazine, whereas the targeting and spacer components are prepared by assembly, using standard fluorenylmethyloxycarbonylbased solid-phase peptide synthesis. The second step involves inserting the disulfide cleavable linkage on desacetylvinblastine hydrazide by reaction with the heterobifunctional reagent (2-[benzotriazole-1-yl-(oxycarbonyloxy)-ethyldisulfanyl]pyridine). The final reaction comprises a mild thiol-disulfide exchange reaction between the components.

The companion imaging agent has also been developed, and is known as etarfolatide (EC20), which contains a ${ }^{99 m} \mathrm{Tc}-$ based imaging group ${ }^{61}$ (Figure 2). Through an efficient solid-phase synthetic procedure, a small-molecular-weight peptide derivative of folate (Cys-Asp-Dap-D-Glu-Pte) was produced. A D-Glu enantiomer residue was incorporated

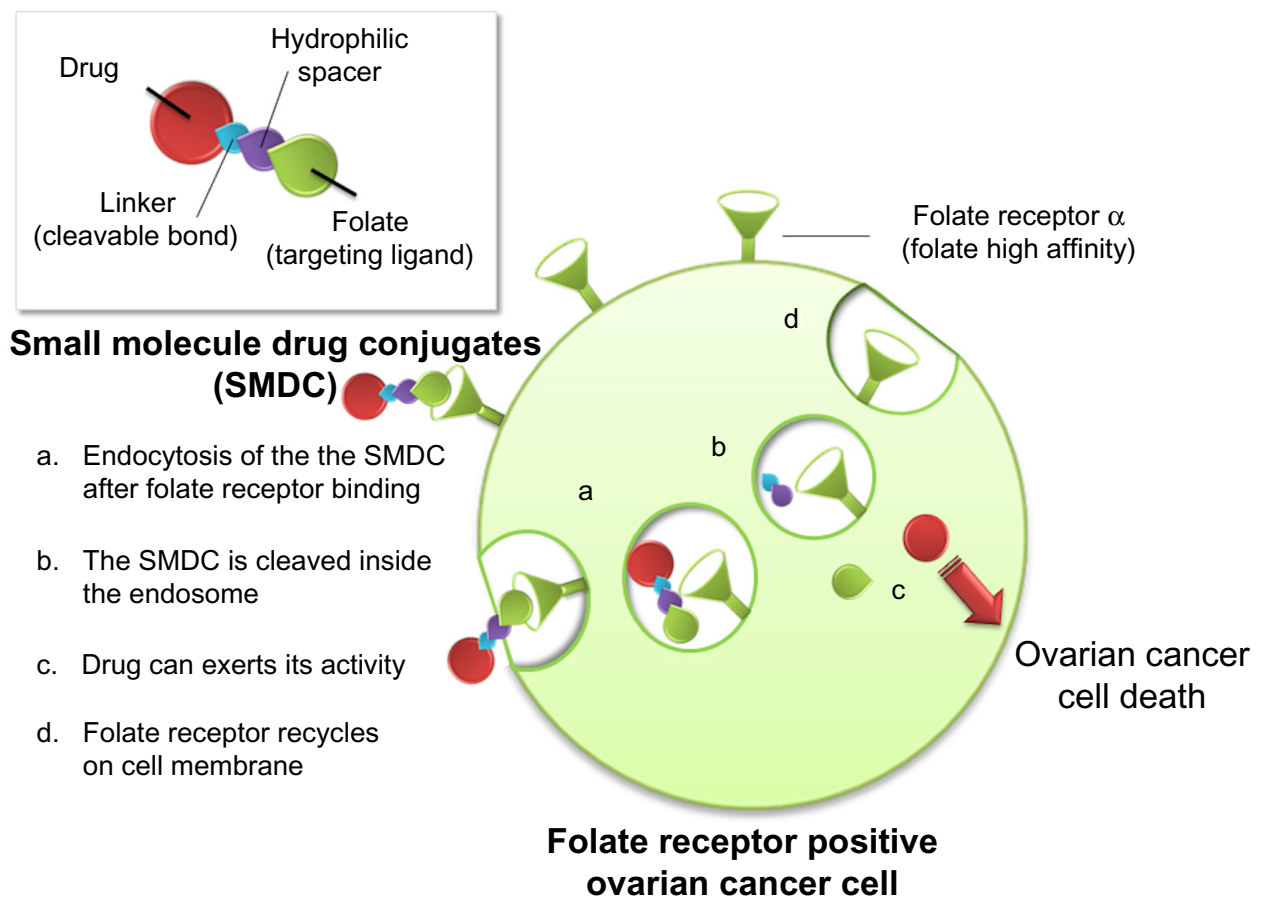

Figure I Mechanism of action of a folate-targeted drug conjugate. 

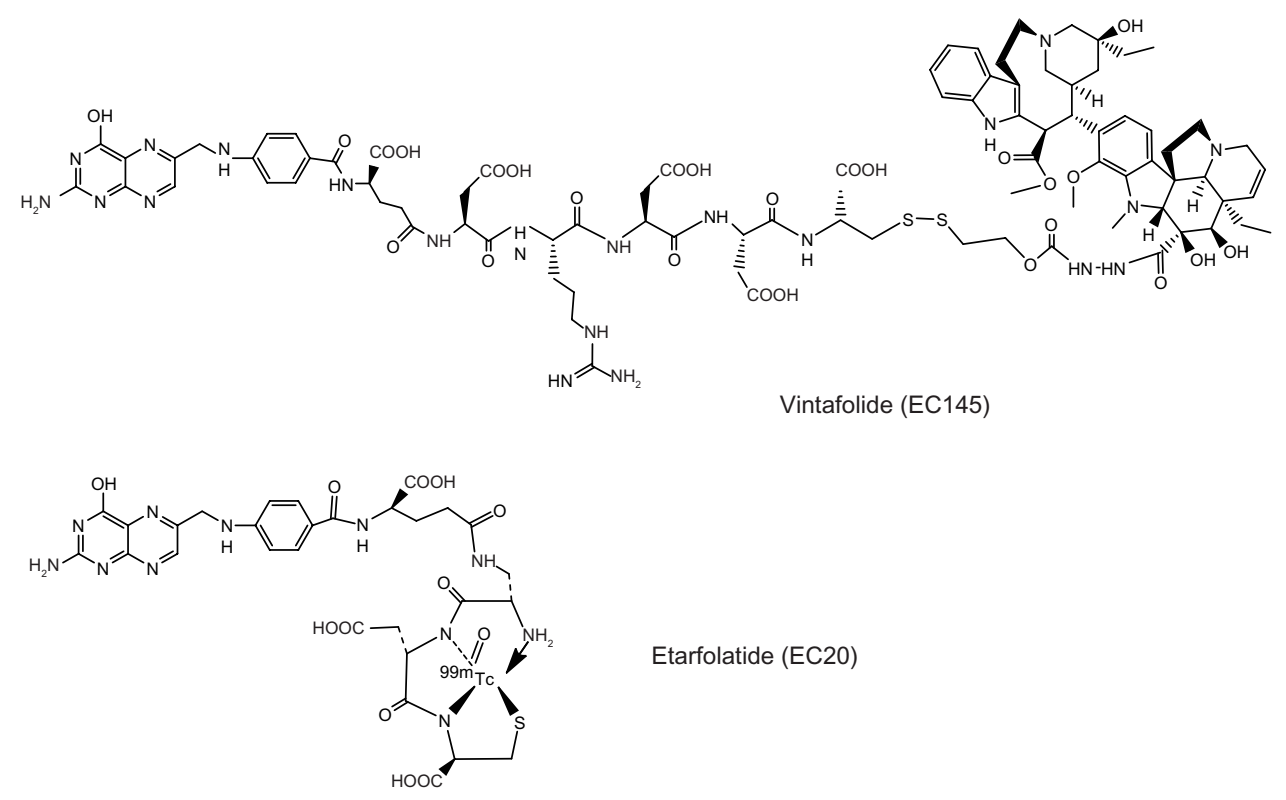

Etarfolatide (EC20)

Figure 2 Structure of folate-targeted therapeutic and diagnostic agents.

into the molecule for the purpose of providing additional metabolic protection against tissue-resident hydrolases, without altering the ability of folic acid to bind to the highaffinity FR. ${ }^{63}$

\section{Efficacy and safety of vintafolide and etarfolatide}

In preliminary work, vintafolide was fully characterized using a KB human nasopharyngeal cancer cell line that overexpresses FR. KB cell lines treated with a short incubation pulse (1-2 hours) of vintafolide showed high cytotoxicity values (around $9 \mathrm{nM}$, versus $2 \mathrm{nM}$ for free vinblastine). The specificity of vintafolide was demonstrated by two methods, ie, using a free folic acid excess in the KB cell line and testing the compounds in the 4T1 FR-negative cell line, in which activity was either completely blocked or not observed.

Vintafolide has been tested in a number of different in vivo models, including M109 mouse lung adenocarcinoma, a KB tumor xenograft model, and aggressive FR-positive J6456 lymphoma. In all these cases, vintafolide exerted a notable antitumor effect. The KB tumor model was also used to evaluate the effect of dosage and treatment schedule on therapeutic efficacy, with different schedules evaluated using a fixed total quantity of $12 \mu \mathrm{mol} / \mathrm{kg}$. The most efficacious ( $100 \%$ cure rate) was found to be that entailing frequent administration of lower doses of vintafolide, ie, once daily for 5 days. Furthermore, etarfolatide, the radiodiagnostic imaging agent, showed that uptake by the liver (nontargeted organ) increased and was proportional to the dose administered. Increased uptake in the liver and a concomitant drop in uptake by the tumor could explain the observed reduction in antitumor effect of vintafolide when administered using the lower-frequency, higher-dose regimens.

Determination of the toxicity of novel anticancer agents, especially those bearing very potent molecules such as desacetylvinblastine hydrazide, is a difficult challenge. In a study in which KB or M109 tumors were grown in mouse models, aside from minimal-to-moderate weight loss during therapy, no other gross toxicity was observed after administration of $5 \mu \mathrm{g} / \mathrm{kg}$ or $10 \mu \mathrm{g} / \mathrm{kg}$ once daily for 5 days. With the exception of the liver, all other tissues appeared to be normal. An important finding was the lack of renal toxicity, despite the fact that mouse kidneys express very high levels of FR. ${ }^{64}$

The first clinical pharmacokinetic evaluation was reported in a single-center, dose-escalation, open-label, Phase I clinical trial (EC-FV-01, NCT00308269) completed in 2007, which involved 32 patients with refractory or metastatic solid tumors (six affected by ovarian cancer) ${ }^{65}$ Vintafolide was administered either as an intravenous injection on days 1, 3, 5 (week 1) and days 15, 17, 19 (week 3 ) of a 4-week cycle at doses of 1.2, 2.5 and $4.0 \mathrm{mg}$ (in three, ten, three patients, respectively), or as a one-hour infusion administered on the same schedule at doses of $2.5 \mathrm{mg}$ and $3 \mathrm{mg}$ (ten and six patients, respectively).

The pharmacokinetic profile is accurately described by a two-compartment model, and is characterized by rapid distribution and elimination (half-life 6 and 26 minutes, respectively). The area under the concentrationtime curve values for administration of $2.5 \mathrm{mg}$ as an 
intravenous bolus or as a one-hour infusion were equivalent (42-40 hours*ng/mL), while the time to peak concentration values were $129 \mathrm{ng} / \mathrm{mL}$ and $42 \mathrm{ng} / \mathrm{mL}$, respectively. The same study also included a population analysis, in which vintafolide showed a clearance of $56.1 \mathrm{~L} /$ hour, with an interindividual variability of $48 \%$ and an interoccasion variability of $8 \%$. Significant covariance of clearance with body surface area was found, although other covariates not tested in the study may account for a larger proportion of the interindividual variability. The volume of distribution at steady-state was $26 \mathrm{~L} .{ }^{66}$ From the pharmacokinetic and clinically relevant toxicity evaluations performed in this trial, a well tolerated intravenous bolus dose of $2.5 \mathrm{mg}$ was recommended as the dose to be used in the Phase II trial.

Regarding diagnostics for recurrent ovarian carcinoma,

${ }^{111}$ In-DTPA-folate was the first FR-targeted low-molecularweight agent to enter clinical trials. ${ }^{67}$ Due to the relatively long half-life and high cost of ${ }^{111} \mathrm{In}$, a ${ }^{99 \mathrm{~m}} \mathrm{Tc}$-based imaging agent (half-life 6 hours) was greatly preferable; etarfolatide was tested and radiopharmaceutical analysis showed it to have a time-dependent and concentration-dependent association with FR-positive cells. It appeared to accumulate preferentially within FR-positive tumors, and to do so in large amounts. Furthermore, its rapid pharmacokinetics (cleared from the blood with a half-life of 4 minutes) improves its quality for use as a diagnostic imaging agent. ${ }^{63}$

An in vivo pilot study was performed to determine the percentages of various solid tumors that accumulate etarfolatide, and to correlate its uptake with immunohistochemistry analysis of FR expression in available biopsied tumor tissue from 154 patients. ${ }^{68}$ As determined by immunohistochemistry staining for the FR $\alpha$ isoform, $67 \%$ of these patients had FR-positive tumors. Overall, the etarfolatide evaluation corresponded to the immunohistochemistry staining result in $61 \%$ of patients. Agreement between etarfolatide-positive results and FR-positive results was $72 \%$, whereas agreement between etarfolatide-negative results and FR-negative results was $38 \%$. This relatively poor agreement between imaging and immunohistochemistry results may be explained in part by the fact that the study was not designed as a lesionto-lesion comparison between the two methods. The study authors suggest that the discrepant results for the two methods may reflect a difference in FR status of the primary neoplasm versus metastatic disease after excision of the primary tumor, or a difference in FR expression between metastatic lesions in the same patient. ${ }^{68}$ Administration of etarfolatide was safe, and the investigators considered that none of the 17 serious adverse events were "related" to administration of the imaging agent. Rather than diagnosis, the primary purpose of etarfolatide administration is currently as a companion agent to enable preselection of patients whose tumors are highly FR-positive, and who thus constitute the best candidates for FR-targeted therapy. Etarfolatide has been a component of more than 16 clinical trials in over 500 patients with ovarian, endometrial, renal, pituitary, and pulmonary cancers, and has been shown to be valuable for predicting response to FR-targeted chemotherapy.

Clinical studies to evaluate the safety and efficacy of vintafolide started in 2007 with a nonrandomized Phase II clinical trial (NCT00507741, EC-FV-02) ${ }^{69}$ in patients with advanced ovarian, fallopian tube, or primary peritoneal carcinoma, after identification of FR expression using etarfolatide ( $n=47$, median age 61 years). The trial, completed at the end of 2012, examined two different doses of vintafolide, administered three times a week on weeks 1 and 3 (4-week cycle). The primary endpoint was the percentage of patients deriving clinical benefit. The disease control rate (complete response + partial response + stable disease) at 8 weeks in patients receiving vintafolide as third-line or fourth-line intravenous therapy was $75 \%$, compared (historically) with a rate of $47 \%$ in women receiving second-line or third-line PEGylated liposomal doxorubicin (hereafter PLD). ${ }^{19,70}$ There were also three partial responses.

From this study, it appeared that vintafolide was very well tolerated, with minimal toxicity. Fatigue was the most common grade 3 toxicity, occurring in $8.2 \%$ of patients. ${ }^{71}$ In this initial trial, the patients were not preselected by expression of FR; however, the lesional uptake of etarfolatide was assessed retrospectively to determine whether the level of radioactive positivity in tumors correlated with vintafolide response rates. ${ }^{72}$ Evaluable tumor lesions $(n=145)$ were classified according to three levels of etarfolatide uptake (ie,,,+++-$)$. The probability of a response was greater with + than with - lesions $(P=0.0022)$. The disease control rate was $57 \%(++), 36 \%(+)$, and $33 \%(-)$ for patients with differently responsive lesions, whereas the disease control rate was $42.2 \%$ for all lesions regardless of response status. The overall response rate was $14 \%$ for patients with the most strongly positive lesions, and $0 \%$ for patients with less positive or negative lesions. Among a subgroup of patients who had failed fewer than three previous treatments, a disease control rate of $86 \%$ was observed for patients with high etarfolatide uptake $(++)$, compared with $50 \%(+)$ and $0 \%$ for those with less reactive lesions (-). The group of patients with highly reactive lesions had a median overall survival of 63.4 weeks, compared with 23.1 weeks using pooled data from all other patients; in addition, a trend towards longer survival was observed in the first group of patients $(P=0.071){ }^{72}$ 
An international, randomized Phase II study (EC-FV-04, NCT00722592, Platinum Resistant Ovarian Cancer Evaluation of Doxil and EC145 Combination Therapy [PRECEDENT]) completed in 2013 compared coadministration of vintafolide and PLD with a liposome formulation alone in women with platinum-resistant ovarian cancer $(n=149){ }^{73}$ Patients were randomized to receive vintafolide $(2.5 \mathrm{mg}$ on days 1,3 and 5 and days 15,17 and 19 of each 4-week cycle) plus PLD (50 mg/m² intravenously, on day 1 of each 4-week cycle) or PLD alone (at the same dosage/schedule) until disease progression or death. No statistically significant difference between the study arms was found with regard to total adverse events. An interim analysis (conducted after the 46th event, of a planned study total of 95 progressions or deaths) indicated that median progression-free survival was 20 weeks for women receiving vintafolide plus PLD $(P=0.014)$, compared with 10.8 weeks in the PLD alone group. ${ }^{74}$ Vintafolide plus PLD was the first combination to show a statistically significant increase in progression-free survival (versus controls) for women with platinum-resistant ovarian cancer. Another combination, ie, trabectedin/PLD, appeared only to benefit the partially platinum-sensitive subgroup. The full evaluation of this study has very recently been published. ${ }^{75} \mathrm{To}$ evaluate the association between progression-free survival, hazard ratio, and level of FR positivity, a threshold analysis was conducted based on etarfolatide scan results (Table 2). Benefit was observed in patients with FR positive disease (10\% to $90 \%$, FR $10 \%-90 \%$ ), and in patients with $100 \%$ of lesions positive for FR (FR 100\%); it was greatest in FR $100 \%$ patients, with a median progression-free survival of 22 weeks compared with 6.6 weeks for PLD alone. Of note, FR $100 \%$ patients in the PLD arm seemed to have a poorer prognosis, with the shortest median progression-free survival of any group (1.5 months); this is consistent with reports regarding the correlation between FR expression and poor outcome. ${ }^{48}$ Based on these promising results, a randomized, double-blind, placebo-controlled Phase III study (NCT01170650, Study for Women With Platinum Resistant Ovarian Cancer Evaluating EC145 in Combination With Doxil ${ }^{\circledR}$ [PROCEED]) is currently recruiting patients with platinum-resistant ovarian cancer. ${ }^{76}$ At baseline, patients undergo etarfolatide imaging to identify FR-positive lesions; they are then randomized to vintafolide with or without PLD. PLD $50 \mathrm{mg} / \mathrm{m}^{2}$ is administered on day 1 of a 4-week cycle and treatment continues until the maximum allowable cumulative dose $\left(550 \mathrm{mg} / \mathrm{m}^{2}\right)$ is reached, or until disease progression or intolerable toxicity. Vintafolide $2.5 \mathrm{mg}$ or placebo is administered on days $1,3,5,15,17$, and 19 of a 4-week cycle, and treatment can continue for up to 20 cycles, or until unacceptable toxicity or disease progression. The primary objective is to assess progression-free survival based on investigator assessment (Response Evaluation Criteria In Solid Tumors version 1.1) in FR-positive patients. ${ }^{77}$ Secondary objectives include investigation of overall survival, safety/ tolerability, overall response rate, and disease control rate. ${ }^{78}$ Table 3 summarizes the main characteristics of the clinical trials described here.

The FR-targeted approach is currently being investigated in breast cancer. An open-label, randomized Phase IIa trial is underway to evaluate the safety and efficacy of vintafolide and the vintafolide plus paclitaxel combination in subjects with advanced triple-negative breast cancer; etarfolatide was used for subject selection (NCT01953536). ${ }^{79}$ A Phase I study of the safety of vintafolide in combination with carboplatin and paclitaxel in patients with FR-reactive endometrial cancer (NCT01688791) is ongoing. ${ }^{80}$

\section{Adverse effects}

The adverse effects of vinblastine are important, relate to its hematologic toxicity, and are dose-limiting; in addition, nausea, constipation, mucositis, and stomatitis are common. Neurotoxicity occurs less frequently than with vincristine, and is characterized by peripheral neuropathy ${ }^{81}$ Vinblastine is a vesicant, and extravasation precautions must be applied.

Table 2 Threshold analysis of progression-free survival in patients with platinum-resistant ovarian cancer based on etarfolatide scan

\begin{tabular}{|c|c|c|c|c|c|c|c|c|c|}
\hline \multirow[t]{2}{*}{ Status } & \multicolumn{3}{|c|}{ Vintafolide + PLD arm } & \multicolumn{6}{|c|}{ PLD alone arm } \\
\hline & $\begin{array}{l}\text { No. of } \\
\text { Patients }\end{array}$ & $\begin{array}{l}\text { Total } \\
\text { Events }\end{array}$ & $\begin{array}{l}\text { Median PFS } \\
\text { (months) }\end{array}$ & $\begin{array}{l}\text { No. of } \\
\text { Patients }\end{array}$ & $\begin{array}{l}\text { Total } \\
\text { Events }\end{array}$ & $\begin{array}{l}\text { Median PFS } \\
\text { (months) }\end{array}$ & HR & $95 \% \mathrm{Cl}$ & P-value \\
\hline mITT & 100 & 62 & 5.0 & 49 & 33 & 2.7 & 0.626 & $0.409-0.959$ & 0.031 \\
\hline FR $10 \%-100 \%$ & 48 & 30 & 5.7 & 26 & 19 & 1.7 & 0.547 & $0.304-0.983$ & 0.041 \\
\hline FR $100 \%$ & 23 & 15 & 5.5 & 15 & 13 & 1.5 & 0.381 & $0.172-0.845$ & 0.013 \\
\hline FR $10 \%-90 \%$ & 25 & 15 & 5.7 & II & 6 & 7.0 & 0.873 & $0.334-2.277$ & 0.790 \\
\hline FR 0\% & 13 & 8 & 3.8 & 7 & 2 & 5.4 & 1.806 & $0.369-8.833$ & 0.468 \\
\hline
\end{tabular}

Note: Reprinted with permission. (c) 2013 American Society of Clinical Oncology. All rights reserved. Naumann RW, Coleman RL, Burger RA, et al. PRECEDENT: a randomized Phase II trial comparing vintafolide (ECI45) and pegylated liposomal doxorubicin (PLD) in combination versus PLD alone in patients with platinum-resistant ovarian cancer. J Clin Oncol. 2013;3I(35):4400-4406. ${ }^{74}$

Abbreviations: FR, folate receptor; HR, hazard ratio; $\mathrm{Cl}$, confidence interval; mITT, intent-to-treat population of patients with measurable disease; PFS, progression-free survival; PLD, PEGylated liposomal doxorubicin. 





When evaluating folate-directed vinblastine conjugates, care must be taken to guard against any potential nephrotoxicity due to the high expression of FR in the kidneys. During a doseescalating clinical trial in 32 patients, vintafolide was generally well tolerated. Decreased gastrointestinal motility (constipation) and peripheral sensory neuropathy were reported as adverse events. Twenty-six of the 32 patients reported at least one drug-related adverse effect. Constipation appeared to be dose-dependent, predictors were found to be clearance and area under the concentration-time curve ${ }^{65}$ Dose-limiting toxicity at $4 \mathrm{mg}$ included reversible ileus and neuropathy. The same adverse effects (all grades/grade $\geq 3$ ) were observed during the EC-FV-03 study in the 22 patients for whom full toxicity data were available, ie, fatigue (8/1), constipation (6/0), anorexia $(5 / 1)$, weight loss $(3 / 0)$, and dyspepsia $(2 / 0){ }^{82}$

The safety data collected during the NCT00722592 (PRECEDENT) trial showed that there were no cumulative treatment-emergent adverse events except for palmar-plantar erythrodysesthesia syndrome, which is frequently related to PLD. The frequencies of leukopenia, neutropenia, abdominal pain, and peripheral sensory neuropathy were significantly higher in the vintafolide plus PLD arm than in the PLD arm. No drug-related mortality or statistically significant difference in incidence of serious drug-related events was observed between treatment arms, and all adverse events occurred in fewer than $5 \%$ of patients, with the exception of small bowel obstruction (vintafolide plus PLD arm, 8.4\%; PLD arm, $12 \%) .{ }^{75}$ However, despite clinical efforts to minimize the adverse effects of vintafolide, peripheral neuropathy remains an important toxicity. A possible strategy to avoid peripheral neurotoxicity might be to seek a balance between the potential therapeutic efficacy of high doses and the potential of such doses to cause painful peripheral neuropathy.

\section{Place in therapy}

Epithelial ovarian cancer is the most lethal gynecological malignancy among women worldwide. Most women present with advanced disease, and despite excellent responses to initial surgery and chemotherapy, 5-year survival statistics remain poor. Among several new therapeutic approaches for ovarian cancer, FR-targeted agents show significant promise. ${ }^{58,83}$ The fact that $F R \alpha$ is overexpressed in ovarian and other cancer cells, while its expression is limited in normal tissues, accentuates its potential as a diagnostic and therapeutic target. ${ }^{54,83}$ Strategies of this sort might allow treatment to be selected based on a tumor's molecular characteristics, advancing therapy from empirical cytotoxic therapies to more individualized ones.
Vintafolide, administered in combination with PLD, is the first combination to lead to a statistically significant increase in progression-free survival for women with platinumresistant ovarian cancer. Our knowledge of FR has very recently been enhanced through crystallographic models, which reveal representative stages of endocytic trafficking and conformation changes occurring in FRs. ${ }^{84}$ These data would appear to provide a platform from which to rationally design drugs as lead compounds with greater selectivity, together with excellent diagnostic agents, which together can greatly reduce nonspecific effects; this may lead to the development of more potent but safer therapeutic agents. However, as may be seen in the case of vintafolide, the time lag between design and clinical use is still several years. ${ }^{85}$

In the future, prescreening a patient's FR status using etarfolatide may also become a companion diagnostic tool for other FR-targeted agents. Etarfolatide might be used to select FR-positive patients and, in combination with fluorescent folate-targeted compounds, could allow more precise removal of tumor tissue. ${ }^{86}$

In conclusion, vintafolide is showing itself to be an important tool in the treatment of ovarian cancer, particularly for the patient population with platinum-resistant ovarian cancer, for whom the prognosis is very poor. These promising new possibilities, if confirmed, will mark the achievement of a new goal in oncology; by utilizing targeted therapy, there is the possibility of targeting therapy to the area where a specific molecular target is present, in this case a marker of ovarian cancer. ${ }^{87}$ The FR-targeting approach is also steadily improving, delivering more than one type of cytotoxic agent to tumors simultaneously. In this next generation of conjugates, folate is tethered to two different drug molecules, eg, mitomycin $\mathrm{C}$ and vinca alkaloids, with distinct biological mechanisms of action. ${ }^{88}$

\section{Acknowledgment}

The work was partially funded by "MIUR Finanziamento Locale".

\section{Disclosure}

The authors report no conflicts of interest in this work.

\section{References}

1. Siegel R, Naishadham D, Jemal A. Cancer Statistics, 2012. CA Cancer J Clin. 2012;62:10-29.

2. Whittemore AS. Characteristics relating to ovarian cancer risk: implications for prevention and detection. Gynecol Oncol. 1994; 55(3 II):S15-S9.

3. Garg PP, Kerlikowske K, Subak L, Grady D. Hormone replacement therapy and the risk of epithelial ovarian carcinoma: a meta-analysis. Obstet Gynecol. 1998;92(3):472-479. 
4. Purdie D, Green A, Bain C, et al. Reproductive and other factors and risk of epithelial ovarian cancer: an Australian case-control study. Int J Cancer. 1995;62(6):678-684.

5. Risch HA, Howe GR. Pelvic inflammatory disease and the risk of epithelial ovarian cancer. Cancer Epidemiol Biomarkers Prev. 1995;4(5): $447-451$.

6. Schildkraut JM, Schwingl PJ, Bastos E, EvanoffA, Hughes C, Curtin JP. Epithelial ovarian cancer risk among women with polycystic ovary syndrome. Obstet Gynecol. 1996;88(4 Pt 1):554-549.

7. Beral V, Hermon C, Peto R, et al. Ovarian cancer and body size: Individual participant meta-analysis including 25, 157 women with ovarian cancer from 47 epidemiological studies. PLoS Med. 2012;9(4):e1001200.

8. La Vecchia C, Decarli A, Negri E, et al. Dietary factors and the risk of epithelial ovarian cancer. J Natl Cancer Inst. 1987;79(4):663-669.

9. Gilsing AMJ, Weijenberg MP, Goldbohm RA, Van Den Brandt PA, Schouten LJ. Consumption of dietary fat and meat and risk of ovarian cancer in the Netherlands Cohort Study. Am J Clin Nutr. 2011;93(1):118-1126.

10. Hunn J, Rodriguez GC. Ovarian cancer: etiology, risk factors, and epidemiology. Clin Obstet Gynecol. 2012;55(1):3-23.

11. Mackay HJ, Brady MF, Oza AM, et al. Prognostic relevance of uncommon ovarian histology in women with stage III/IV epithelial ovarian cancer. Int J Gynecol Cancer. 2010;20(6):945-952.

12. Omura GA, Brady MF, Homesley HD, et al. Long-term follow-up and prognostic factor analysis in advanced ovarian carcinoma: the Gynecologic Oncology Group experience. J Clin Oncol. 1991;9(7):1138-1150.

13. Fader AN, Rose PG. Role of surgery in ovarian carcinoma. J Clin Oncol. 2007;25(20):2873-2883.

14. Aabo K, Adams M, Adnitt P, et al. Chemotherapy in advanced ovarian cancer: Four systematic meta-analyses of individual patient data from 37 randomized trials. Br J Cancer. 1998;78(11):1479-1487.

15. Ozols RF, Bundy BN, Greer BE, et al; Gynecologic Oncology Group. Phase III trial of carboplatin and paclitaxel compared with cisplatin and paclitaxel in patients with optimally resected stage III ovarian cancer: a Gynecologic Oncology Group study. J Clin Oncol. 2003;21(17):3194-3200.

16. Crane LM, Arts HJ, van Oosten M, et al. The effect of chemotherapy on expression of folate receptor-alpha in ovarian cancer. Cell Oncol. 2012;35(1):9-18.

17. Leamon CP, Lovejoy CD, Nguyen B. Patient selection and targeted treatment in the management of platinum-resistant ovarian cancer. Pharmgenomics Pers Med. 2013;6(1):113-125.

18. Yap TA, Carden CP, Kaye SB. Beyond chemotherapy: targeted therapies in ovarian cancer. Nat Rev Cancer. 2009;9(3):167-181.

19. Naumann RW, Coleman RL. Management strategies for recurrent platinum-resistant ovarian cancer. Drugs. 2011;71(11):1397-1412.

20. Marburger JHI, Kvamme FE. Priorities for Personalized Medicine. 2008; US President's Council of Advisors on Science and Technology. Available from: http:/www.whitehouse.gov/files/documents/ostp/ PCAST/pcast_report_v2.pdf. Accessed December 19, 2013.

21. Druker BJ, Talpaz M, Resta DJ, et al. Efficacy and safety of a specific inhibitor of the BCR-ABL tyrosine kinase in chronic myeloid leukemia. N Engl J Med. 2001;344(14):1031-1037.

22. Saltz LB, Meropol NJ, Loehrer PJ Sr, Needle MN, Kopit J, Mayer RJ. Phase II trial of cetuximab in patients with refractory colorectal cancer that expresses the epidermal growth factor receptor. J Clin Oncol. 2004;22(7):1201-1208.

23. Cunningham D, Humblet Y, Siena S, et al. Cetuximab monotherapy and cetuximab plus irinotecan in irinotecan-refractory metastatic colorectal cancer. N Engl J Med. 2004;351(4):337-345.

24. Van Cutsem E, Peeters M, Siena S, et al. Open-label phase III trial of panitumumab plus best supportive care compared with best supportive care alone in patients with chemotherapy- refractory metastatic colorectal cancer. J Clin Oncol. 2007;25(13):1658-1664.

25. Spiegelstein O, Eudy JD, Finnell RH. Identification of two putative novel folate receptor genes in humans and mouse. Gene. 2000;258(1-2): $117-125$.
26. Saikawa Y. Structural and functional analysis of the human kb cell folate receptor gene $\mathrm{P} 4$ promoter: cooperation of three clustered spl-binding sites with initiator region for basal promoter activity. Biochemistry. 1995;34(31):9951-9961.

27. Kamen BA, Wang MT, Streckfuss AJ, Peryea X, Anderson RGW. Delivery of folates to the cytoplasm of MA104 cells is mediated by a surface membrane receptor that recycles. J Biol Chem. 1988;263(27): $13602-13609$

28. Leamon CP, Low PS. Delivery of macromolecules into living cells: a method that exploits folate receptor endocytosis. Proc Natl Acad Sci US A. 1991;88(13):5572-5576.

29. Turek JJ, Leamon CP, Low PS. Endocytosis of folate-protein conjugates: ultrastructural localization in KB cells. J Cell Sci. 1993;106(1): $423-430$.

30. Wu M, Fan J, Gunning W, Ratnam M. Clustering of GPI-anchored folate receptor independent of both cross-linking and association with caveolin. J Membr Biol. 1997;159(2):137-147.

31. Shen F, Ross JF, Wang X, Ratnam M. Identification of a novel folate receptor, a truncated receptor, and receptor type beta in hematopoietic cells: cDNA cloning, expression, immunoreactivity, and tissue specificity. Biochemistry. 1994;33(5):1209-1215.

32. Wang J, Gunning W, Kelley KMM, Ratnam M. Evidence for segregation of heterologous GPI-anchored proteins into separate lipid rafts within the plasma membrane. J Membr Biol. 2002;189(1):35-43.

33. Maziarz KM, Monaco HL, Shen F, Ratnam M. Complete mapping of divergent amino acids responsible for differential ligand binding of folate receptors alpha and beta. J Biol Chem. 1999;274(16):11086-11091.

34. Shen F, Zheng X, Wang J, Ratnam M. Identification of amino acid residues that determine the differential ligand specificities of folate receptors alpha and beta. Biochemistry. 1997;36(20):6157-6163.

35. Elwood PC, Kane MA, Portillo RM, Kolhouse JF. The isolation, characterization, and comparison of the membrane-associated and soluble folate-binding proteins from human KB cells. J Biol Chem. 1986;261(33):15416-15423.

36. Antony AC, Utley CS, Marcell PD, Kolhouse JF. Isolation, characterization, and comparison of the solubilized particulate and soluble folate binding proteins from human milk. J Biol Chem. 1982;257(17):10081-10089.

37. Yang XY, Mackins JY, Li QJ, Antony AC. Isolation and characterization of a folate receptor-directed metalloprotease from human placenta. J Biol Chem. 1996;271(19):11493-11499.

38. Antony AC, Verma RS, Unune AR, LaRosa JA. Identification of a Mg2+-dependent protease in human placenta which cleaves hydrophobic folate-binding proteins to hydrophilic forms. J Biol Chem. 1989;264(4):1911-1914.

39. Luhrs CA, Slomiany BL. A human membrane-associated folate binding protein is anchored by a glycosyl-phosphatidylinositol tail. J Biol Chem. 1989;264(36):21446-21449.

40. Wang J, Shen F, Yan W, Wu M, Ratnam M. Proteolysis of the carboxyl-terminal GPI signal independent of GPI modification as a mechanism for selective protein secretion. Biochemistry. 1997;36(47): 14583-14592.

41. Coney LR, Tomassetti A, Carayannopoulos L, et al. Cloning of a tumor-associated antigen: MOv18 and MOv19 antibodies recognize a folate-binding protein. Cancer Res. 1991;51(22):6125-6132.

42. Miotti S, Canevari S, Ménard S, et al. Characterization of human ovarian carcinoma-associated antigens defined by novel monoclonal antibodies with tumor-restricted specificity. Int J Cancer. 1987;39(3):297-303.

43. Chen YL, Chang MC, Huang CY, et al. Serous ovarian carcinoma patients with high alpha-folate receptor had reducing survival and cytotoxic chemo-response. Mol Oncol. 2012;6(3):360-369.

44. Antony AC. Folate receptors. Annu Rev Nutr. 1996;16:501-521.

45. Miotti S, Bagnoli M, Tomassetti A, Colnaghi MI, Canevari S. Interaction of folate receptor with signaling molecules lyn and $G$ alpha(i-3) in detergent-resistant complexes from the ovary carcinoma cell line IGROV1. J Cell Sci. 2000;113(2):349-357. 
46. Tomassetti A, Mangiarotti F, Mazzi M, et al. The variant hepatocyte nuclear factor 1 activates the $\mathrm{P} 1$ promoter of the human beta folate receptor gene in ovarian carcinoma. Cancer Res. 2003;63(3):696-704.

47. Kelemen LE. The role of folate receptor alpha in cancer development, progression and treatment: cause, consequence or innocent bystander? Int $J$ Cancer. 2006;119(2):243-250.

48. Toffoli G, Cernigoi C, Russo A, Gallo A, Bagnoli M, Boiocchi M. Overexpression of folate binding protein in ovarian cancers. Int J Cancer. 1997;74(2):193-198.

49. Toffoli G, Russo A, Gallo A, et al. Expression of folate binding protein as a prognostic factor for response to platinum-containing chemotherapy and survival in human ovarian cancer. Int J Cancer. 1998;79(2): 121-126.

50. Fisher DE. Apoptosis in cancer therapy: crossing the threshold. Cell. 1994;78(4):539-542.

51. Righetti SC, Della Torre G, Pilotti S, et al. A comparative study of p53 gene mutations, protein accumulation, and response to cisplatin-based chemotherapy in advanced ovarian carcinoma. Cancer Res. 1996;56(4): 689-693.

52. Garin-Chesa P, Campbell I, Saigo PE, Lewis JL Jr, Old LJ, Rettig WJ. Trophoblast and ovarian cancer antigen LK26: sensitivity and specificity in immunopathology and molecular identification as a folate-binding protein. Am J Pathol. 1993;142(2):557-567.

53. Zacchetti A, Martin F, Luison E, et al. Antitumor effects of a human dimeric antibody fragment 131I- AFRA-DFM5.3 in a mouse model for ovarian cancer. J Nucl Med. 2011;52(12):1938-1946.

54. Konner JA, Bell-McGuinn KM, Sabbatini P, et al. Farletuzumab, a humanized monoclonal antibody against folate receptor $\alpha$ in epithelial ovarian cancer: a phase I study. Clin Cancer Res. 2010;16(21) 5288-5295.

55. Armstrong DK, White AJ, Weil SC, Phillips M, Coleman RL. Farletuzumab (a monoclonal antibody against folate receptor alpha) in relapsed platinum-sensitive ovarian cancer. Gynecol Oncol. 2013;129(3):452-458.

56. Morphotek. A Safety and efficacy study of farletuzumab in subjects with adenocarcinoma of the lung. Available from: http://clinicaltrials. gov/show/NCT01218516. NLM identifier: NCT01218516. Accessed January 1, 2014.

57. Morphotek. An efficacy and safety study of MORAb-003 in platinumresistant or refractory relapsed ovarian cancer (FAR-122). Available from: http:/clinicaltrials.gov/show/NCT00738699. NLM identifier: NCT00738699. Accessed January 1, 2014.

58. Teng L, Xie J, Teng L, Lee RJ. Clinical translation of folate receptortargeted therapeutics. Expert Opin Drug Deliv. 2012;9(8):901-908.

59. Leamon CP, Low PS. Folate-mediated targeting: from diagnostics to drug and gene delivery. Drug Discov Today. 2001;6(1):44-51.

60. Leamon CP, Reddy JA. Folate-targeted chemotherapy. Adv Drug Deliv Rev. 2004;56(8):1127-1141.

61. Vlahov IR, Leamon CP. Engineering folate-drug conjugates to target cancer: from chemistry to clinic. Bioconjug Chem. 2012;23(7): 1357-1369.

62. Dosio F, Milla P, Cattel L. EC-145, a folate-targeted vinca alkaloid conjugate for the potential treatment of folate receptor-expressing cancers. Curr Opin Investig Drugs. 2010;11(12):1424-1433.

63. Leamon CP, Parker MA, Vlahov IR, et al. Synthesis and biological evaluation of EC20: a new folate-derived, ${ }^{99 \mathrm{~m}} \mathrm{Tc}$-based radiopharmaceutical. Bioconjug Chem. 2002;13(6):1200-1210.

64. Leamon CP, Reddy JA, Vlahov IR, et al. Comparative preclinical activity of the folate-targeted vinca alkaloid conjugates EC140 and EC145. Int J Cancer. 2007;121(7):1585-1592.

65. Li J, Sausville EA, Klein PJ, et al. Clinical pharmacokinetics and exposure-toxicity relationship of a folate-vinca alkaloid conjugate EC145 in cancer patients. J Clin Pharmacol. 2009;49(12):1467-1476.

66. LoRusso PM, Edelman MJ, Bever SL, et al. Phase I study of folate conjugate EC145 (vintafolide) in patients with refractory solid tumors. J Clin Oncol. 2012;30(32):4011-4016.
67. Siegel BA, Dehdashti F, Mutch DG, et al. Evaluation of 111In-DTPAfolate as a receptor-targeted diagnostic agent for ovarian cancer: initial clinical results. J Nucl Med. 2003;44(5):700-707.

68. Fisher RE, Siegel BA, Edell SL, et al. Exploratory study of ${ }^{99 \mathrm{~m}}$ Tc-EC20 imaging for identifying patients with folate receptor-positive solid tumors. J Nucl Med. 2008;49(6):899-906.

69. Merck Sharp and Dohme Corp. Study of EC145 in patients with advanced ovarian and endometrial cancers. Available from: http:// clinicaltrials.gov/show/NCT00507741. NLM identifier: NCT00507741. Accessed January 1, 2014

70. Lawrie TA, Bryant A, Cameron A, Gray E, Morrison J. Pegylated liposomal doxorubicin for relapsed epithelial ovarian cancer. Cochrane Database Syst Rev. 2013;7:CD006910.

71. Naumann RW, Morris R, Harb W, et al. Protocol EC-FV-02: a phase II study of ec145 in patients with advanced ovarian cancer. Presented the 16th International Meeting of the European Society of Gynaecological Oncology, Belgrade, Serbia, October 11-14, 2009.

72. Symanowski JT, Maurer AH, Naumann RW, Shah NP, Morgenstern D, Messman RA. Use of ${ }^{99 m}$ Tc-EC20 (a folate-targeted imaging agent) to predict response to therapy with EC145 (folate-targeted therapy) in advanced ovarian cancer. J Clin Oncol. 2010;28(Suppl 15): Abstr 5034.

73. Merck Sharp and Dohme Corp. Platinum resistant ovarian cancer evaluation of doxil and EC145 combination therapy (PRECEDENT). Available from: http://clinicaltrials.gov/show/ NCT00722592. NLM identifier: NCT00722592. Accessed January 3, 2014.

74. Naumann RW, Symanowski JT, Ghamande SA, et al. PRECEDENT: a randomized phase II trial comparing EC145 and pegylated liposomal doxorubicin (PLD) in combination, versus PLD alone, in subjects with platinum-resistant ovarian cancer. J Clin Oncol. 2010; 28(Suppl 18):LBA5012b.

75. Naumann RW, Coleman RL, Burger RA, et al. PRECEDENT: a randomized Phase II trial comparing vintafolide (EC145) and pegylated liposomal doxorubicin (PLD) in combination versus PLD alone in patients with platinum-resistant ovarian cancer. J Clin Oncol. 2013;31(35):4400-4406.

76. Merck Sharp and Dohme Corp. Study for women with platinum resistant ovarian cancer evaluating EC145 in combination with doxil $^{\circledR}$ (PROCEED). Available from: http://clinicaltrials.gov/show/ NCT01170650. NLM identifier: NCT01170650. Accessed January 3, 2014.

77. Eisenhauer EA, Therasse P, Bogaerts J, et al. New response evaluation criteria in solid tumours: Revised RECIST guideline (version 1.1). Eur J Cancer. 2009;45:228-247.

78. Naumann RW, Gilbert L, Miller AM, et al. A randomized doubleblind phase III trial comparing vintafolide plus pegylated liposoma doxorubicin (PLD) versus PLD plus placebo in patients with platinum-resistant ovarian cancer (PROCEED). J Clin Oncol. 2013;31: TPS5613.

79. Merck Sharp and Dohme Corp. Safety and efficacy study of vintafolide and vintafolide plus paclitaxel compared to paclitaxel alone in participants with Triple Negative Breast Cancer (TNBC) (MK-8109-004). Available from: http://clinicaltrials.gov/show/NCT01953536. NLM identifier: NCT01953536. Accessed January 3, 2014.

80. Merck Sharp and Dohme Corp. A study of MK-8109 (vintafolide) given alone or with chemotherapy in participants with advanced cancers (MK-8109-001). Available from: http://clinicaltrials.gov/show/ NCT01688791. NLM identifier: NCT01688791. Accessed January 3, 2014.

81. Chong C, Logothetis C, Savaraj N, Fritsche H, Gietner A, Samuels M. The correlation of vinblastine pharmacokinetics to toxicity in testicular cancer patients. J Clin Pharmacol. 1988;28(8):714-718.

82. Garon EB, Harb WA, Pal SE, et al. EC-FV-03: a phase II study of EC145 (folate-receptor targeted therapy) in patients with advanced lung cancer. J Thorac Oncol. 2009;4 Suppl 1:S452. 
83. Markert S, Lassmann S, Gabriel B, et al. Alpha-folate receptor expression in epithelial ovarian carcinoma and non-neoplastic ovarian tissue. Anticancer Res. 2008;28(6A):3567-3572.

84. Wibowo AS, Singh M, Reeder KM, et al. Structures of human folate receptors reveal biological trafficking states and diversity in folate and antifolate recognition. Proc Natl Acad Sci U S A. 2013;110(38): $15180-15188$

85. Walters CL, Arend RC, Armstrong DK, Naumann RW, Alvarez RD. Folate and folate receptor alpha antagonists mechanism of action in ovarian cancer. Gynecol Oncol. 2013;131(2):493-498.
86. van Dam GM, Themelis G, Crane LM, et al. Intraoperative tumorspecific fluorescence imaging in ovarian cancer by folate receptor- $\alpha$ targeting: first in-human results. Nat Med. 2011;17(10):1315-1319.

87. Zajchowski DA, Karlan BY, Shawver LK. Treatment-related protein biomarker expression differs between primary and recurrent ovarian carcinomas. Mol Cancer Ther. 2012;11(2):492-502.

88. Vlahov IR, Santhapuram HK, Wang Y, et al. An assembly concept for the consecutive introduction of unsymmetrical disulfide bonds: synthesis of a releasable multidrug conjugate of folic acid. J Org Chem. 2007;72(16):5968-5972.

\section{Publish your work in this journal}

Pharmacogenomics and Personalized Medicine is an international, peerreviewed, open access journal characterizing the influence of genotype on pharmacology leading to the development of personalized treatment programs and individualized drug selection for improved safety, efficacy and sustainability. This journal is indexed on the American Chemical
Society's Chemical Abstracts Service (CAS). The manuscript management system is completely online and includes a very quick and fair peer-review system, which is all easy to use. Visit http://www.dovepress. com/testimonials.php to read real quotes from published authors.

Submit your manuscript here: http://www.dovepress.com/pharmacogenomics-and-personalized-medicine-journal 